Tropical Journal of Pharmaceutical Research December 2013; 12 (6): 1093-1095

ISSN: $1596-5996$ (print); 1596-9827 (electronic)

(C) Pharmacotherapy Group, Faculty of Pharmacy, University of Benin, Benin City, 300001 Nigeria.

All rights reserved.

Available online at http://www.tjpr.org http://dx.doi.org/10.4314/tjpr.v12i6.34

\title{
Commentary
}

\section{Engaging Community Pharmacists and Alternative Practitioners: An Approach to Active Case Finding of Tuberculosis in Malaysia}

\author{
Muhammad Atif ${ }^{1 *}$, Syed Azhar Syed Sulaiman ${ }^{1}$, Asrul Akmal Shafie ${ }^{2}$, \\ Muhammad Asif ${ }^{3}$ and Shazia Qasim Jamshed ${ }^{4}$ \\ ${ }^{1}$ Discipline of Clinical Pharmacy, ${ }^{2}$ Discipline of Social and Administrative Pharmacy, ${ }^{4}$ Department of Pharmacology, School of \\ Pharmaceutical Sciences, Universiti Sains Malaysia, 11800, Minden, Penang, ${ }^{4}$ School of Pharmacy, International Islamic \\ University, Kuantan, Pahang, Malaysia.
}

*For correspondence: Email: pharmacist_atif@yahoo.com; Tel: +60147572474

Revised accepted: 8 November 2013

\begin{abstract}
Contact tracing is the most commonly employed process of identifying the relevant contacts of a person with an infectious disease. A systematic review and meta-analysis on contact tracing of tuberculosis (TB) suspects has shown that the yield of household contact investigation in low- and middle-income countries was $6.5 \%$. However, a recent study from Malaysia has shown the yield of TB contact tracing as low as $0.49 \%$. Engaging community pharmacists and alternative practitioners in tracing TB suspects in Malaysia is context-specific and can significantly decrease transmission and incidence of the disease.
\end{abstract}

Tropical Journal of Pharmaceutical Research is indexed by Science Citation Index (SciSearch), Scopus, International Pharmaceutical Abstract, Chemical Abstracts, Embase, Index Copernicus, EBSCO, African Index Medicus, JournalSeek, Journal Citation Reports/Science Edition, Directory of Open Access Journals (DOAJ), African Journal Online, Bioline International, Open-J-Gate and Pharmacy Abstracts

Tuberculosis (TB) is a global health tragedy with an incidence of nine million cases every year. With an estimated two million deaths every year, it is one of the leading causes of adult mortality. Malaysia is ranked as an intermediate-burden country with an estimated 81 new cases per 100,000 in 2011. From 2000 to 2011, nationwide TB case notification has increased from 16,000 to 20,666 cases. It is thus imperative to comprehend that an amalgamation of incomplete case detection and protracted diagnostic delays renders steady transmission of TB in the community. One potential strategy in controlling the growing incidence of TB is early case detection by actively screening general population and/or higher risk groups [1]. Population-wide mass-screening is not recommended in resource-limited countries due to high cost per identified case. However, screening in high risk groups and adequately prioritized contacts can be a realistic and effective approach [1].

Contact tracing is the most commonly employed process of identifying the relevant contacts of a person with an infectious disease (the index patient) and ensuring they are aware of their exposure. Contact investigation identifies both relatively smaller group of people with active TB and those already have infection without disease. Although the standard TB treatment should be immediately started in active TB patients, people in latter category may also be candidates for treatment. Contact investigation is often complementary to "passive case finding" that can significantly improve case detection and thereby can reduce the transmission of the disease. Prioritization of contacts and diagnostic strategy 
are the deep seated components of contact tracing process. There are several countryspecific guidelines that advocate case finding through prioritization of contacts as high, moderate and low [2-4].

However, there are no internationally agreed criteria on how to prioritize high risk groups and what screening approaches to be employed. While many countries are currently adopting various modalities to screen suspected TB cases, 'Stop TB Department' of World Health Organization (WHO) recommends that the national TB screening strategy should be context specific, and based on the local epidemiological, demographic and health system situation [1].

Morrison and co-workers in their systematic review and meta-analysis on contact tracing of TB suspects has shown that the yield of household contact investigation in low and middle income countries was $6.5 \%$ (bacteriologically confirmed and clinically diagnosed). Several other studies have shown the yield of contact tracing ranging from 0.2 to $7.8 \%$ (active TB), in which the highest yield was obtained in Brazil [5]. Recently, a study from Malaysia [6] has shown that the yield of contact investigation for all active cases was as low as $0.49 \%$, while among all those investigated, Tuberculin Skin Test (TST) was positive in less than $4.0 \%$ contacts. These findings showned that the yield of contact tracing was significantly lower than the findings from low- and middleincome countries, presumably due to inappropriate prioritization of contacts and absence of clear guidelines on contact investigation of TB suspects. However, such findings are quite common in countries where contact investigation for TB among close contacts is generally accorded low priority due to greater workload imposed on healthcare workers by passively identified active cases [5].

Authors are of the opinion that within the Malaysian context, yield of contact investigation (active case finding) can be significantly improved by tracing TB suspects at three different points of alternative consultation (i.e., community pharmacies, traditional and complementary practitioners, and faith healers), which are usually considered by a sub-group of people prior to visiting speciality clinics. Among these different points of alternative consultations, visit to the community pharmacies is on the lead. People with common ailments like mild cough, fever or allergies etc. visit community pharmacies either to seek advice from pharmacist or for the purpose of self-medication. Although in Malaysia, self-medication is strongly discouraged by medical doctors and pharmacists, yet a large proportion of people purchase over-the-counter (OTC) products for the cough and flu [7]. Some of the cough and flu preparations available at pharmacies fall under alternative preparations and therefore requires no prescriptions from the doctors.

A study conducted by Hassali and co-workers [8] reported that cough and cold preparations are most commonly self-medicated drugs followed by analgesics and gastrointestinal preparations. Most of the participants from the above cited study purchased drugs from pharmacies indicating that the high cost of doctors' visits, long waiting time at hospitals and the availability of affordable drugs led them to alternative ways to source medications for their minor illnesses. Similar findings on self-medication have been reported elsewhere [9]. Keeping in view the current practices of Malaysians and strong relationship between cough and $\mathrm{TB}$, authors are of the opinion that pharmacists should be actively involved in active case finding of TB.

Staff at pharmacies should be trained enough to identify TB suspects complaining cough and mild fever, which are indeed leading causes of selfmedication in the community. These suggestions are consistent with the recommendations of WHO paper on the role of pharmacist as a health promoter in terms of their participation in health screening programs to identify those at risk in the community [9].

The second most common site of alternative consultation is a visit to traditional and complementary (TCAM) medical practitioner. TCAM use is common both in developed and developing countries. Studies from the United States of America show an increase in TCAM use. Similarly, people from developing countries (eg, Africa, Asia and Latin America) use TCAM for their common ailments [10]. Likewise, TCAM use is widespread among Malaysians [10, 11] partly as a result of Malaysia's rich tropical biodiversity which continues to provide a reliable source of natural products, frequently used by indigenous medical practices. Unlike other Asian countries, the Ministry of Health (MoH) Malaysia has instituted registration of TCAM practitioners. However, the registration is not compulsory due to lack of legislation [12]. Within the Malaysian context where there is upsurge in the use of TCAM, National Tuberculosis Program (NTP) managers can use platform of TCAM practitioners to stratify high risk TB groups by 
convincing them for referring suspected TB patients to Directly Observed Treatment, Shortcourse (DOTS) centre.

Traditional beliefs such as "evil eye", Satan and witchcraft are the most common perceived causes of TB among various communities. In Malaysia, faith healers being another frequently visited alternative point of consultation are selected by sect of people who consider themselves to be possessed by the evil spirits. As these faith healers practice in "clinics" and entertain "patients" who are "cured" through nontraditional methods, the Malaysian government has decided to register them with Traditional \& Complementary Division (T\&CMD) [13]. Therefore, it is viable to engage faith healers in identifying highly suspected TB patients. However, unlike TCAM practitioners, faith healers have limited knowledge about the biomedical aspects and thus require extensive TB training to ensure their active participation in contact investigation process.

\section{CONCLUSION}

While uniform international guidelines on screening for active TB cases are still awaited, it is strongly recommended that TB suspects in Malaysia should be traced through an adequate prioritization process. Competency on the part of the contact investigation staff is a key to the success of the process. Moreover, the prioritization process can be further enhanced by engaging community pharmacies which are often the first contact of person with a cough, mild fever and associated symptoms. Similarly, alternative practitioners are the other options in that a larger sect of people prefers to consult them for their common ailments. Productive cough of more than 3 weeks can be used as a cut-off value by pharmacists and alternative practitioners for referring the suspects to the DOTS centre. All these measures can significantly improve the yield of contact tracing and consequently may result in gradual decrease in the incidence of TB in Malaysia and countries with similar statistics and practices.

\section{REFERENCES}

1. Stop TB Department. Scoping meeting for the development of guidelines on screening for active TB. [cited 2013 Aug 29]. Available from: http://www.who.int/tb/TBscreeningmeetingreport20 11.pdf.

2. Centers for Disease Control and Prevention. Guidelines for the investigation of contacts of persons with infectious tuberculosis; recommendations from the National Tuberculosis Controllers Association and $C D C$, and Guidelines for using the QuantiFERON@-TB Gold test for detecting Mycobacterium tuberculosis infection, United States. MMWR, 2005; 54(No. RR-15).

3. Richard S, Kerri V. Guidelines for tuberculosis contact tracing in Pacific Island countries and territories; 2010. ISBN: 978-982-00-0411-5.

4. National Institute for Health and Clinical Excellence. Tuberculosis; Clinical diagnosis and management of tuberculosis, and measures for its prevention and control, 2006. [cited 2013 Aug 29]. Available from: $\quad$ www.nice.org.uk/nicemedia/pdf/CG33quick reffguide.pdf

5. Morrison J, Pai M, Hopewell PC. Tuberculosis and latent tuberculosis infection in close contacts of people with pulmonary tuberculosis in low-income and middle-income countries: a systematic review and meta-analysis. Lancet Infect Dis. 2008; 8: 359-368

6. Atif M, Sulaiman SA, Shafie AA, Ali I, Asif M. Tracing contacts of $T B$ patients in Malaysia: costs and practicality. SpringerPlus. 2012;1(1):40.

7. NewStraitTimes. Self-medication carries risks. Malaysia, 2012. [cited 2013 Aug 29]. Available from: http://www.nst.com.my/nation/general/selfmedication-carries-risks 1.72381? locallinksEnabled=false.

8. Hassali MA, Shafie AA, Al-Qazaz H, Tambyappa J, Palaian S, Hariraj V. Self-medication practices among adult population attending community pharmacies in Malaysia: an exploratory study. Int J Clin Pharm, 2011; 33(5): 794-799.

9. World Health Organization. The role of the pharmacist in self-care and self-medication, 1998. [cited 2013 Aug 29]. Available from: http://whqlibdoc.who.int/ hq/1998/WHO DAP 98.13.pdf.

10. Hasan SS, Ahmed SI, Bukhari NI, Loon W. Use of complementary and alternative medicine among patients with chronic diseases at outpatient clinics. Compl Ther Clin Pract, 2009; 15: 152-157.

11. Siti Z, Tahir A, Ida Farah A, Ami Fazlin S, Sondi S, Azman $A$, et al. Use of traditional and complementary medicine in Malaysia: a baseline study. Compl Ther Med, 2009; 17(5/6): 292-299.

12. Ministry of Health (MOH). Traditional \& Complementary Division, 2012. [cited 2013 Aug 29]. Available from: http://tcm.moh.gov.my/v4/.

13. A BIG MESSAGE for an upside down world. Malaysia Faith Healers to Be Registered; 2010. [cited 2013 Aug 29]. Available from: http://www.abigmessage. $\mathrm{com} /$ malaysia-faith-healers-to-be-registered.html. 